\title{
The Application of Digital Media Technology in Animation Design and Production
}

\author{
An Wang ${ }^{1, a}$, Hao $\mathrm{Lu}^{2, \mathrm{~b}}$ \\ ${ }^{1}$ Jiangxi Science \& Technology Normal University, Nanchang, China \\ 2 Jiangxi Vocational \& Technical College of Information Application, Nanchang, China \\ awanganwangmenghua@163.com; ' $\mathrm{lh} 880223 @ 163 . c o m$
}

Keywords: Animation Design; Digital Media; Influence; Application

\begin{abstract}
As the digital information era comes, the continuous development of science and technology and information technology stimulates digital media technology to be widely used in various fields of social life, including film and television, media, games, advertising, animation and other fields, which is inseparable with people's lives. Similarly, digital media technology plays a very important role in animation design. In the field of animation design, digital media technology is the inevitable trend of the future development of the animation industry. Further research on the relationship between animation design and digital media is of great significance to the healthy and sustainable development of Chinese animation industry. The paper briefly introduces the meaning of digital media, presents the impact of digital media on animation design, and discusses the application of the digital media technology to China's animation design, and puts forward some suggestions on how to promote further development of China's animation design under the influence of digital media.
\end{abstract}

\section{Introduction}

On the basis of the development of information technology, digital media technology has gradually been applied in all walks of life, and contributes to the realization of the era of information technology. Animation design and production, as a new industry supporting for the development of Chinese information industry, is brought different technical support by digital media in the process of development. The application of digital media in animation design and production has close relationship with the rise and fall of Chinese animation industry. Therefore, exploring the relationship between digital media and animation design has positive effect on the healthy development of Chinese animation industry.

\section{The connotation of digital media technology}

Digital media is named the media spread and existed in digital form. It is based on digital technology and takes the screen as the carrier of information. At present, digital movies, internet media, digital TV, digital newspaper and so on, can be called digital media. Compared with the traditional mass media, the spread of digital media can greatly enhance the interactivity and digital communication. Digital media technology can break the restrictions of time, space and media, and express the idea of the creators more directly in animation works. At present, the digital media technology combines computer graphics, computer network technology, communication technology, two-dimensional animation, three-dimensional animation and other multi-directional contents.

\section{The effect of digital media technology in animation design and production}

Change the performance form. In the new era of media art, it has a variety of forms. The mobile phone, film, flash sketch and digital animation film are closely connected with the film and television drama. For digital art, its characteristics of compatibility, sharing and open greatly change the traditional means of communication and achieve disruptive change on the traditional situation in 
the field when communicating with mass media, information industry and telecommunication industry. At the same time, it also makes the mass communication change to more specific classification when producing new industries. For information technology, each change produced in the process of development will have impact on Chinese media industry, gradually realizing the integration of mobile phones, radio and the internet.

Enrich the production forms. Through the digital media technology, animation design and production have more new materials and new tools, which greatly enrich the expressive ability of artistic language. At present, many animation writers input the works into the computer when creating works to design what they desire through the application of the software. For example, if the photos are imported into the software, it can acquire the effect the camera can not capture after certain treatment, and can also obtain new animation image through the element superposition.

Broaden the performance space of the contents. Compared with traditional art form, the traditional art is restricted by the time, materials and other carriers. But with the development of computer technology, the performance space of art has been extended. Since ancient times and in the further, the picture of the space and time can be produced to realize the macro or micro picture.

Improve creative efficiency. The workload of a complete animation works is very heavy, even the animation of few minutes also needs more than a hundred tricks to achieve the effect of the finished production. In order to ensure the completion of an outstanding work within the specified time, designers must improve their production efficiency. But the use of digital media technology can help the designers to shorten the drawings production efficiency through the software and ensure the quality of drawing presentation, so that the domestic animation production more informationalized and efficient. The effect of digital media increases the output of domestic animation effectively and brings more viewing options for viewers, laying good bedding for the steady development of the animation industry.

\section{The application of digital media technology in animation design and production}

The application of digital media technology in animation design and production of 2D animation. Compared with the traditional animation design and production technology, digital media technology has certain advantages itself for the design and production of two-dimension animation. First, when designing and producing the animation by using digital media technology, the design staff usually take the key frames as the main feature and the display screen is automatically generated y the general equipment according to the key frames completed. As usually, the animation is the intermediate picture, at the same time, the cartoon characters generated automatically is very smooth and clear in sensitivity and reflection speed. Second, in the process of automation design, digital media technology provides convenience for the line color of the character, which is also easy to grasp. The designers only need to click on the automatic processing images; the system will generate the required picture automatically. Therefore, in the teaching, teachers can give full play to the advantages of the two aspects to guide students to carry on color design and motion of cartoon character.

The application of digital media technology in animation design and production of 3D animation. Under the digital background, there is great different between 2D and 3D animation. 2D animation mainly describes the object through simple lines, while 3D animation is more complex, containing the visual effects, light effect, etc. with the continuous development and application of digital media technology, 3D animation design and production has achieved very prominent development in the technique, level and other aspects. 3D animation design and production contains very complex process, including object design, model building, lighting design, key frame setting, animation generation, etc. in each links of 3D animation design and production, digital media technology has very significant effect. To sum up, in the process of animation design and production, the application of digital media technology can shorten the time and improve the precision and special effect, which can stimulate the audience's interest and promote the further development of the animation industry to produce more and more outstanding animation production. 


\section{The suggestions on the development of animation design and production under the digital media era}

It can not rely too much on science and technology. The using of advanced science and technology is to bring the audience more sense of the visual effect. But if over-use, it will have direct impact on the performance quality of the design concept, contrary with the original nature of animation, and the viewer also will lose interest. Therefore, the designers cannot rely on science and technology in the creation, and should adhere to the nature of animation design, keep balance between business and art, so as to ensure the quality and visual effect of animation to provide protection for the sustainable development of domestic animation.

The animation design and production should make full use of digital media technology to cultivate the animation talents needed by the society. In the classroom teaching, students' ability of operation and technical application should be paid attention to. Adhere to integrating the theory teaching with actual teaching, so as to improve the students' level of technical application. When setting and choosing the courses of animation design and production, the overall practical situation should not only be considered, and the application of new digital media technology should also be paid attention to. Especially the study and promotion of new technology should keep pace with the time. In actual teaching process, basic knowledge of animation need to be strengthened, course points needs to be give prominence to, and students' technical application ability need to be focused on, so as to the animation talents process great development potential and adapt to all kinds of job requirements.

Strengthen the promoting action of government in the development of animation design and production. Give full play of the publicizing of the government and encourage the animation designers to broaden the production scope and thinking mode, so as to the animation works close to life. With the rapid development of information technology and the acceleration of globalization, the competition of the animation market is becoming more and fiercer, so the government department needs to coordinate the contradiction between supply and demand and improve the market economic system, which is benefit to the health development of animation industry. At present, there is imbalance between supply and demand. In order to change the situation, the government must strengthen the fight against piracy and resolutely defend the original intellectual property right of animation, and support the animation business with legal measures, so as to promote the sustainable and healthy development of Chinese animation industry.

\section{Summary}

In summary, digital media technology plays increasingly impact under the modern information background. Its application in animation design and production is also more and more wide and attracts more and more attention, so as to makes the animation design and production technology widely developed, cultivate more and more excellent animation talents, and enhance the overall economic benefit of Chinese animation industry.

\section{References}

[1] Kang Feng, Lei Chen, Xing Yang, etc. Research on the training mode of digital media technology specialty based on the industrial demand[J]. Journal of Huainan Normal University, 2014(4).

[2] Lili Wang. Research on the application of digital media technology on animation design[J]. New Media Research, 2016,10:132-133.

[3] Yun Yu. The application of digital media technology in the design and production[J]. information and computer: theory edition, 2014(6):216.

[4] Xiaoqi Xiu. Research on the application of digital media technology on animation design and production[J]. Guide of Sci-tech Magazine, 2014(23):171. 
[5] Wenting Shi. Feasibility study on the construction of digital media technology[J]. Journal of Examinaltion, 2011(21):149-150.

[6] Bei Li. Study on the teaching of creative thinking in digital media[J]. Art Education Research, 2013(24):25-27.

[7] Linlin Yin. Study on the influence of digital media technology on animation design[J]. Journal of Chifeng University( natural science edition), 2015(13):174.

[8] Zhuomin Wang. The innovative application of digital media art in animation design[J]. literature and Artistic Life, 2015(09):136-137. 